\title{
Acute haemorrhagic leucoencephalitis (Hurst) with a concurrent primary herpes simplex infection
}

\author{
ALBERT N. MARTINS, LUDWIG G. KEMPE, AND GEORGE J. HAYES \\ From the Neurosurgery Service, Walter Reed General Hospital, Washington, D.C., U.S.A.
}

In 1941 Hurst described a rapidly progressive acute disease of the central nervous system which he named acute haemorrhagic leucoencephalitis. It is a rare disorder; less than 40 cases have been reported, and its aetiology is still unknown. Before 1963, the reported cases of acute haemorrhagic leucoencephalitis had been diagnosed after death. We have had the opportunity, however, to treat a patient who developed the disease and recovered. The diagnosis was established upon microscopic examination of an amputated temporal lobe. During the early stages of the illness his serum showed a significant rise of the complement-fixing antibody titre to herpes simplex.

We have a two-fold purpose in presenting this case report. First, the opportunity for follow-up evaluation of patients with proven acute haemorrhagic leucoencephalitis is rarely encountered; consequently, we are prompted to make the data which we collected generally available. Secondly, we wish to consider the significance of the unprecedented association which was established between acute haemorrhagic leucoencephalitis and a primary herpes simplex infection.

\section{CASE REPORT}

A 39-year-old right-handed army officer was admitted to Walter Reed General Hospital on September 19, 1961 with the chief complaints of headache and a transient loss of consciousness.

HISTORY He was entirely well until four days before admission at which time he developed an unrelenting headache. Although the headache had been steadily increasing in severity, he was able to work up to the day of admission. Shortly after awakening on the day of admission, he 'passed out' and subsequently was admitted to the hospital.

At a later date, when the patient was able to give a reliable history, additional pertinent information was gathered. During the months preceding the start of his headaches he had been in excellent health; he specifically denied respiratory ailments and febrile episodes. Exposure to toxins was denied as was ingestion of medication which contained arsenic. He had no allergies or symptoms suggestive of an allergic diathesis.

In addition to the information noted above, a detailed anamnesis was collected which disclosed no other pertinent historical events.

PHYSICAL EXAMINATION He was a somnolent caucasian man who was oriented as to time, person, and place and who complained of a severe headache. Although able to slowly answer questions, he could not give a reliable history. Vital signs were normal. The general physical examination and a detailed neurological evaluation were normal except for the following positive and pertinent negative findings. His neck was supple. He could read newsprint but was inattentive to objects confronting his left visual field. The right pupil reacted sluggishly to light and was smaller than the left. There was no abnormality in either the extraocular movements or the appearance of the ocular fundi. He had weakness of the facial musculature and absence of the corneal reflex on the left side. An ill-defined dysarthria was noted. In addition to somatotopagnosia of his left side, he had hemiparesis and hyperactivity of deep tendon reflexes as well as impaired appreciation of all sensory modalities on the left. Plantar, superficial abdominal, and cremasteric reflexes were absent on the left and normal on the right.

LABORATORY DATA Shortly after admission the following information was obtained: white blood cell count, 16,550 per c.mm. with $88 \%$ neutrophils and $12 \%$ lymphocytes. Haematocrit was 43 . Urine analysis was normal. Predominating in the temporal region, a persistent slow wave focus and suppression of activity from the right hemispheric leads, with spread to the left side, were observed on the electroencephalogram (Fig. 1a). Lumbar puncture was not performed.

HOSPITAL COURSE A mass lesion in the right cerebral hemisphere was suspected; accordingly, a right percutaneous carotid angiogram was performed which showed displacement of both the anterior cerebral artery and the internal cerebral vein to the left as well as elevation of the distal ramifications of the middle cerebral artery (Fig. 2a, $b$, and $c$ ). The angiographic findings were judged to be compatible with an expanding process located within the posterior limits of the right temporal lobe.

Seven hours after admission, under halothane anaesthesia with hyperventilation, a right fronto-temporoparietal osteoplastic craniotomy was performed. Upon 


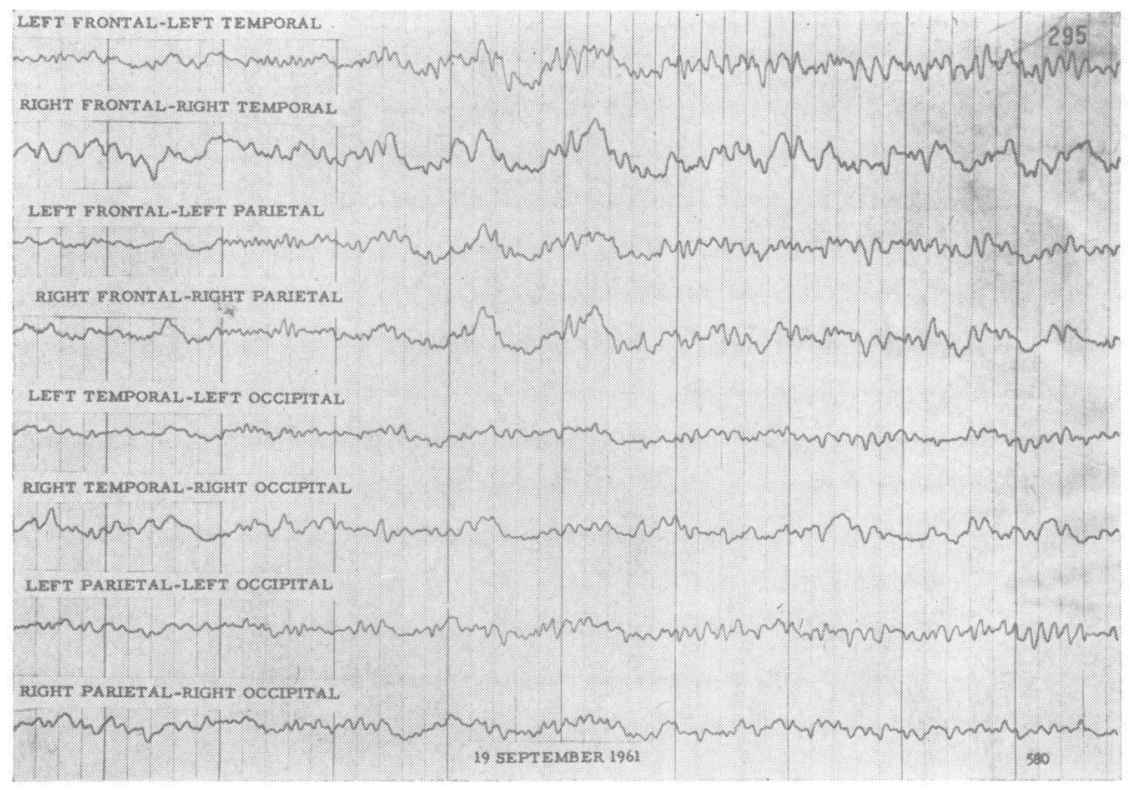

FIG. 1. Electroenct色 phalograms, on admis sion (a) and two yeats later (b). Right-side slow activity with spread to the left-sided leads is seen early in the course of the illness (a). Two years later, the left sided leads are essentis ally normal but righ sided slow activity pe sists (b).

FIG. 1a

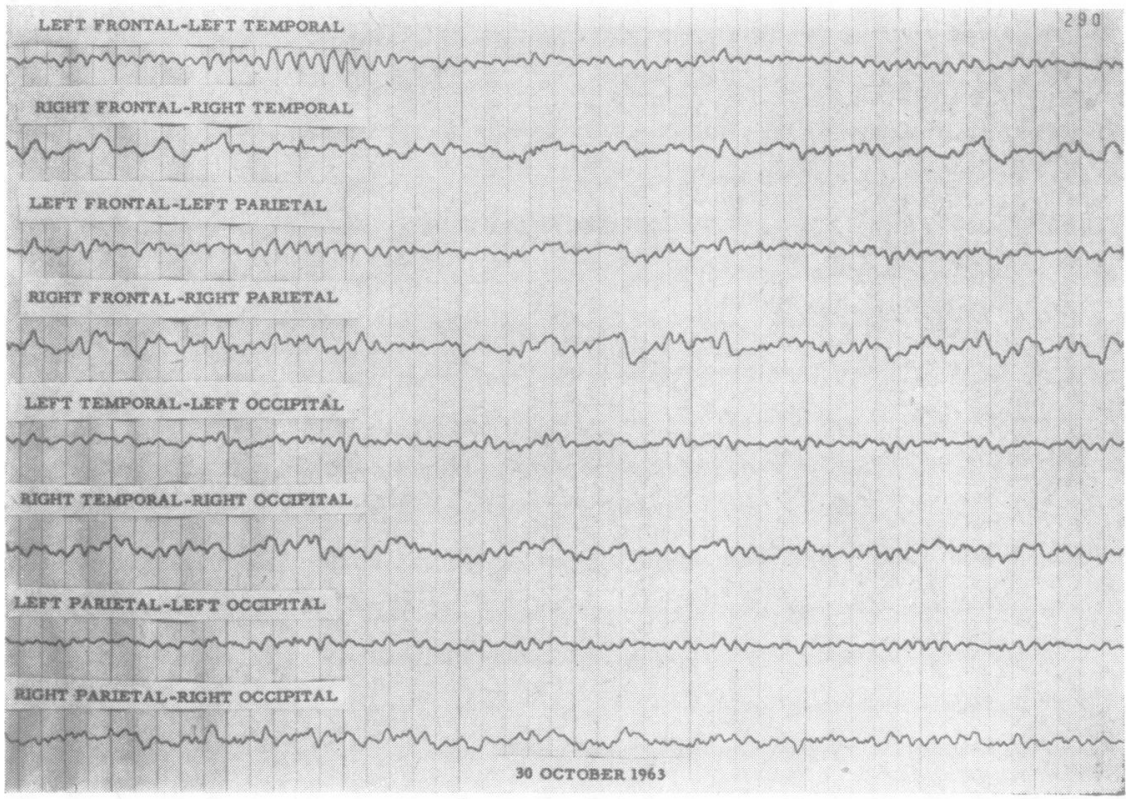

FIG. 1b

exposure of the temporal lobe and contiguous portions of the frontal and parietal lobes, the brain was observed to be oedematous and under increased pressure. The operative findings were felt to be compatible with a diffuse glioma and so the right temporal lobe was amputated. The line of excision was approximately $10 \mathrm{~cm}$. from the temporal lobe tip. The exposed white matter was soft and friable and had multiple, diffusely dispersed petecchial haemorrhages. Dural closure and replacement of the bore flap was accomplished without difficulty.

After surgery the patient's vital signs remained stable He reacted to verbal stimuli within 12 hours after the operation, and by the end of the first post-operative d he accepted and retained oral fluids. With stupor slow but progressively subsiding, he was able to respono coherently to questions asked of him by his family at the 


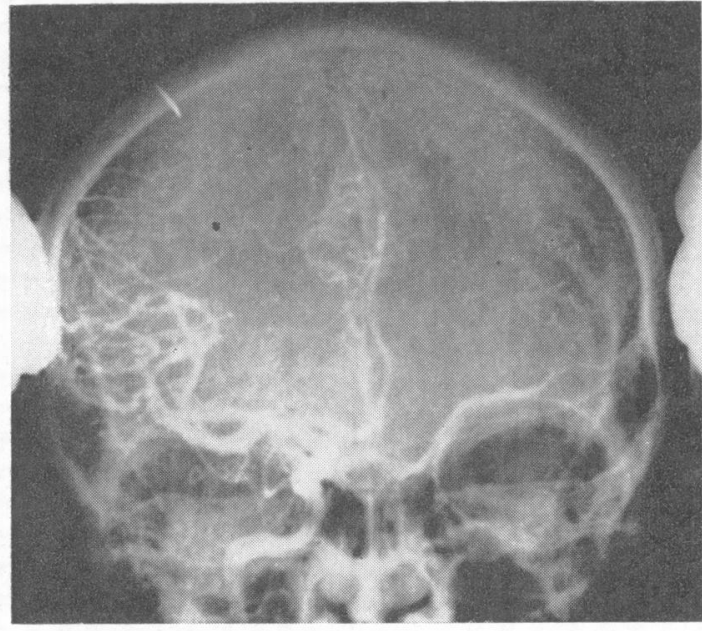

FIG. $2 \mathrm{a}$

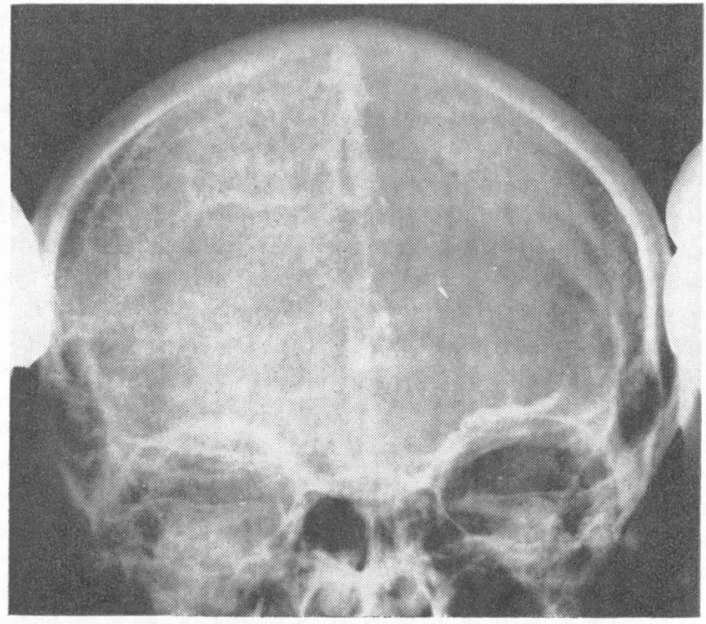

FIG. $2 b$

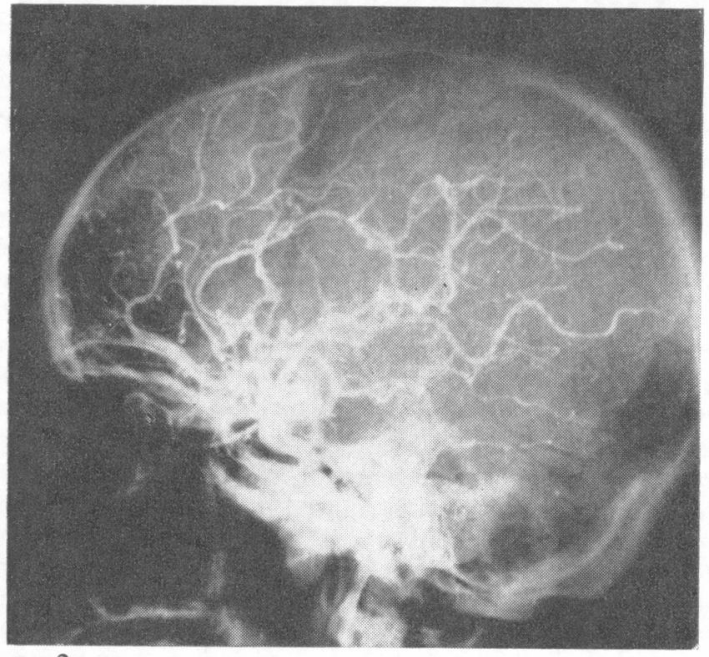

FIG. 2c

FIG. 2. Right carotid angiograms showing displacement of both the anterior cerebral arteries and internal cerebral vein to the left ( $a$ and $b)$, as well as elevation of the branches of the middle cerebral artery $(c)$. end of the first post-operative week. His rectal temperature ranged between $99^{\circ} \mathrm{F}$. and $101^{\circ} \mathrm{F}$. until 7 October, 1961 when it returned to normal by lysis. Post-operative medication consisted of codeine, chloral hydrate, sulphasoxizole, dimenhydrinate, and diphenylhydantoin.

On 25 September 1961 and again on 10 October 1961 blood was drawn for serological studies by the Department of Virus Diseases of the Walter Reed Army Institute of Research, Washington, D.C. The serum drawn on 25 September had no demonstrable complement-fixing antibodies to herpes simplex at a 1:8 dilution. The serum drawn on 10 October, however, had complement-fixing antibodies to herpes simplex at a 1:32 dilution.

By the fourteenth post-operative day the patient was able to get out of bed in a wheelchair. Intermittent confusion and restlessness, which had continued during the second and third post-operative weeks, gave way gradually to orientation.

An electroencephalogram performed on 17 October 1961 showed persistent delta wave activity and suppression of normal activity from the right frontotemporal leads.

During November the following studies were performed and found to be normal: white blood cell count and differential count, serum electrolytes, urine analysis, fasting blood glucose, blood urea nitrogen, and a chest radiograph. Eye examination on 6 November 1961 disclosed a complete left homonymous hemianopsia with macular splitting. At the same time visual acuity was 20/20 in the right eye and 20/40 in the left eye.

Although improvement in his mental and physical status continued during December of 1961, he exhibited wide swings of mood with alternating elation and depression. In the latter part of December, because he tended to deny his infirmities by projection which approached psychotic proportions, he was transferred to the psychiatry service for further evaluation and treatment. Psychometric tests were given to the patient on 31 January 1961. Performance of tasks requiring the use of verbal symbolic ideas as well as immediate and recent memory capabilities were judged to be very superior. His M.Q. on the Wechsler memory scale was $\mathbf{1 3 8}$. His verbal I.Q. was 126 on the Wechsler adult intelligence scale, although his performance I.Q. on the same scale was 74. The visual field deficit was judged not to be the sole factor responsible for the low score on the performance part of the test. His full-scale I.Q. at the time was 104.

The patient's mood lability and paranoid ideation subsided sufficiently so that in March of 1962 he was able to return to work.

TISSUE EXAMINATION The formalin-fixed excised portion of the temporal lobe measured $9 \mathrm{~cm} . \times 5 \mathrm{~cm} . \times 2 \mathrm{~cm}$. On macroscopic examination the meninges and cortex appeared normal. The white matter was soft and friable and contained multiple petecchial haemorrhages.

Microscopic examination was performed on sections prepared from multiple paraffin-imbedded blocks of tissue and stained with haematoxylin and eosin, luxolfast blue (for myelin), cresyl violet, phosphotungstic acid-haematoxylin, and the Bodian silver impregnation method for demonstrating axis cylinders. The meninges and cortex were normal. In addition to showing vacuolization and 'sponginess', the white matter was diffusely 


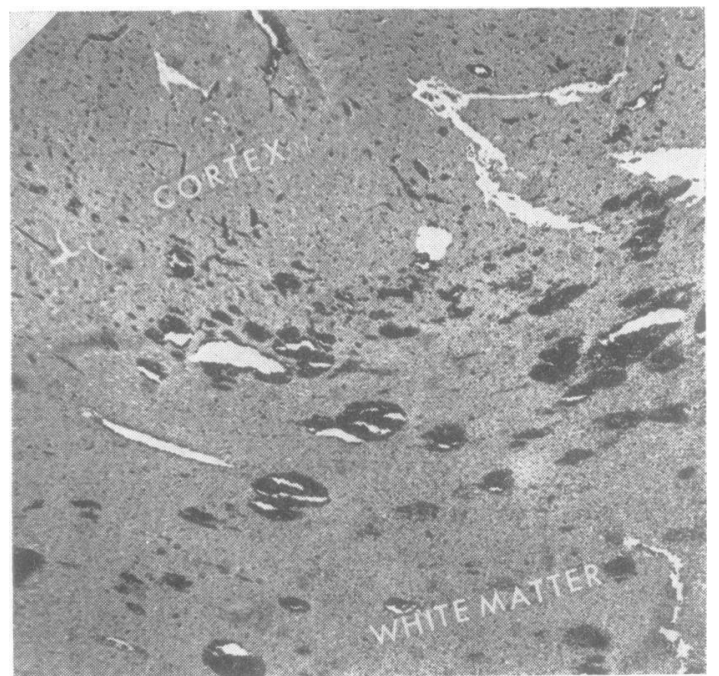

FIG. 3a

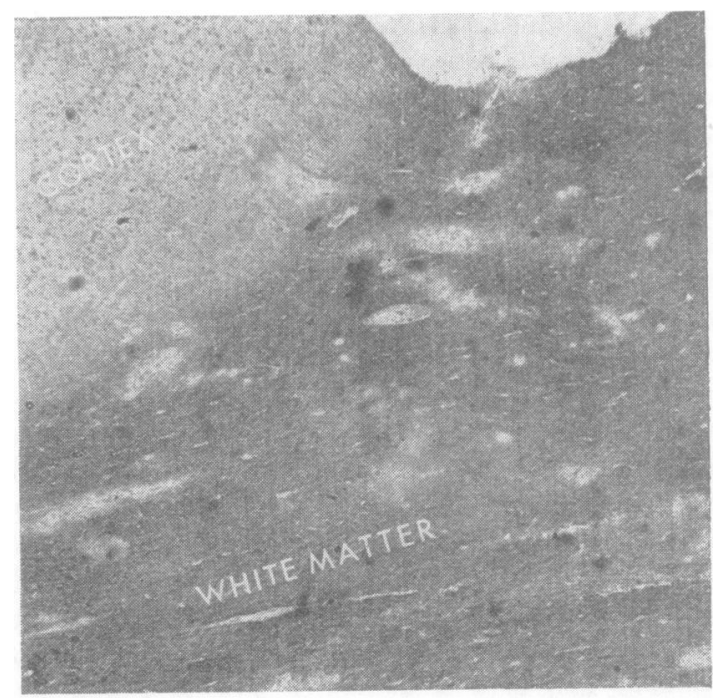

FIG. 3b

FIG. 3. Photomicrographs of sections made from the excised temporal lobe tissue.

(a) 'Ball' and 'ring' haemorrhages scattered diffusely throughout the white matter. Cortex is normal. Haematoxylin and eosin, $\times 13$.

(b) Random demyelination of white matter, more marked around blood vessels. Luxol-fast blue for myelin, $\times 13$.

(c) Loosening of white matter, with haemorrhages and a conspicuous polymorphonuclear leucocytic infiltrate. Haematoxylin and eosin, $\times 110$.

(d) Blood vessel in white matter with intramural and perivascular deposition of fibrinous material which stains darkly (positive) with phosphotungstic acid-haematoxylin, $\times 620$.

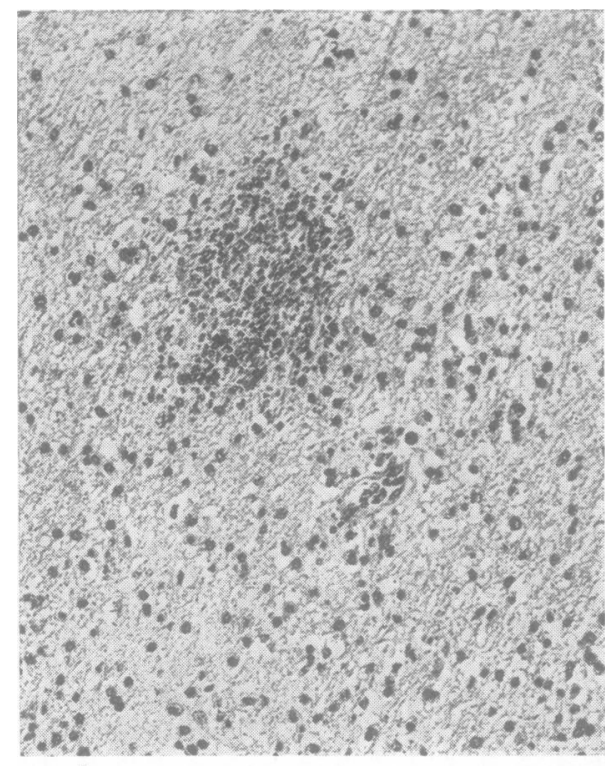

FIG. 3c

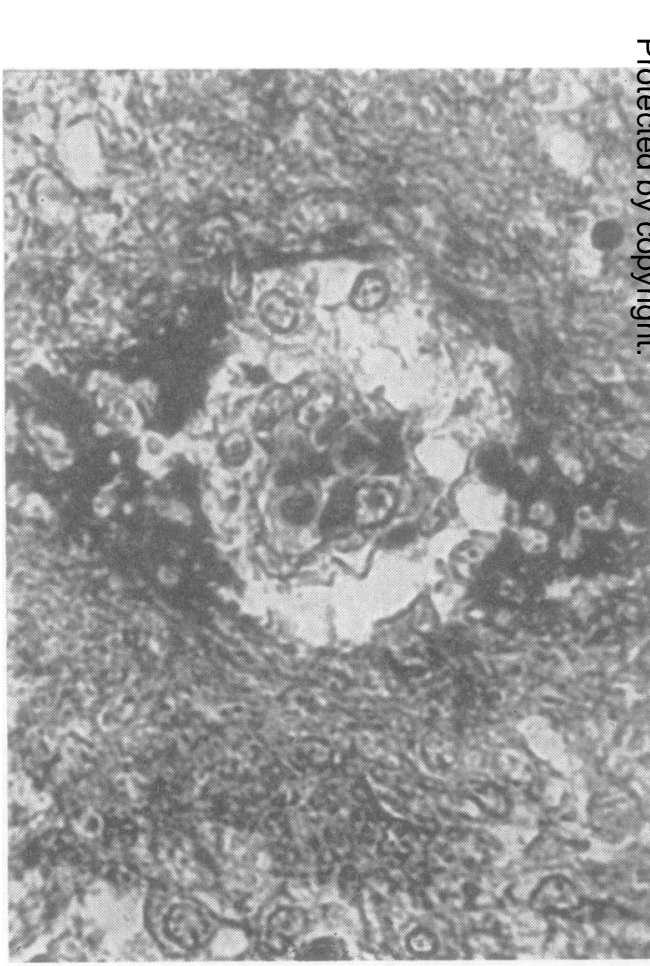

FIG. 3d 


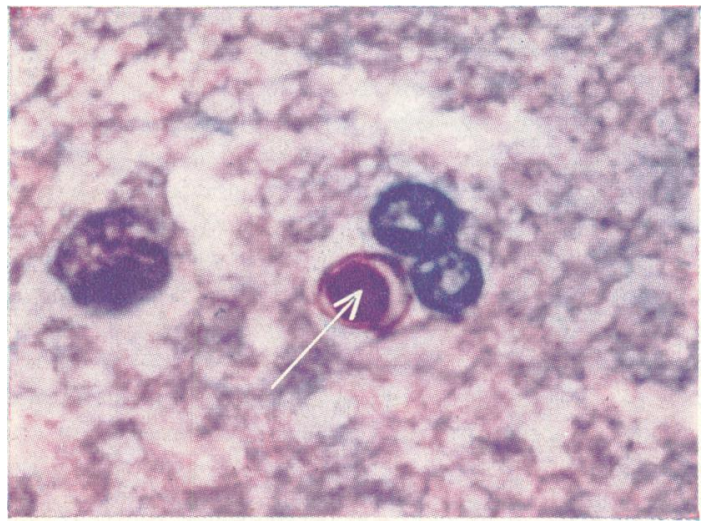

FIG. 4. Oligodendroglia (arrow) in white matter of excised temporal lobe with an intranuclear inclusion. Haematoxylin and eosin $\times 1,200$.

infiltrated with polymorphonuclear leucocytes which were more numerous around blood vessels. Within blood vessel walls and extending into the perivascular parenchyma, material was seen which had fibrin's appearance and staining characteristics. These areas involved with the fibrinous material were otten unassociated with the numerous perivascular 'ball' and 'ring' haemorrhages which were also noted throughout the white matter. Although loss of myelin was observed in a random fashion throughout the white matter, perivascular loss was most prominent and often associated with collections of lipid-laden macrophages. Axis cylinders were noted to be intact in some areas of myelin loss (Fig. 3a-d). Acute haemorrhagic leucoencephalitis was diagnosed. The Armed Forces Institute of Pathology, Washington, D.C., was consulted and corroborated the diagnosis.

At a later date when additional laboratory data had suggested the possibility of a herpes simplex infection, the sections were re-examined. Structures were occasionally seen within the nuclei of oligodendroglia which were interpreted as Cowdry type $\mathrm{A}$ inclusion bodies by a majority of neuropathologists consulted (Fig. 4).

INTERIM HISTORY Supported by monthly visits to the psychiatric clinic, he was able to return to full-time office work approximately 10 months after the onset of his illness.

However, despite his freedom from signs or symptoms which would have indicated recrudescence of encephalitis, the patient had to be re-admitted to Walter Reed General Hospital because of progressive depression and irritability.

SECOND ADMISSION (28 OCTOBER 1963) Physical examination revealed him to be alert, oriented, and cooperative. Speech was coherent, relevant, and goal-directed. Although free of delusions and hallucinations, he manifested suicidal ideation and depression. Recent and remote memory as well as interpretation of proverbs and grasp of concepts were judged to be normal; subtraction of serial sevens was performed with facility. There was a complete left homonymous hemianopsia. The pupils were equal and normally reactive. The corneal reflexes were intact. Tandem gait was slightly ataxic and finger-to-nose and heel-to-shin testing disclosed minimal left-sided dysmetria. There was a slight left hemiparesis, but the deep tendon and superficial reflexes were normal. Appreciation of pain, temperature, vibration, and light touch was intact; however, proprioception and extinction on the left side, which was most marked in the upper extremity, less so in the face, and least in the leg, was impaired. Impairment of stereognosis was also noted on the left. His concept of body-scheme was intact. The remainder of the general physical examination and detailed neurological examination disclosed no other abnormalities.

The following studies were performed and found to be normal; white blood cell count, urine analysis, chest radiograph, electrocardiogram, and a brain scan with $\mathrm{Hg}^{197}$. A lumbar puncture showed the cerebrospinal fluid to be under normal pressure. Cell count and the concentrations of protein, globulin, electrolytes, and glucose in the cerebrospinal fluid were all normal. A serological test for syphilis was negative in both the serum and cerebospinal fluid. In the latter part of March 1964 the serum had no demonstrable complement-fixing antibodies to herpes simplex at a $1: 8$ dilution.

Formal audiometric examination disclosed normal hearing. Opthalmological examination again showed a congruous left homonymous hemianopsia with macular splitting; visual acuity was $20 / 20$ bilaterally. An electroencephalogram performed on 30 October 1963 showed improvement over the previous ones, but right-sided slow activity persisted (Fig. 1b). Repeat psychometric testing on 19 November 1963 showed improvement over results of the previous tests. Full-scale I.Q. was 114. Performance on non-verbal tasks, however, continued to be inferior to his verbal abilities.

His severe depression responded well to a series of eight electric shock treatments and he was subsequently retired from active duty.

He was last examined, as an out-patient, on 3 April 1964. His physical status had not changed from that which was recorded upon his second admission in October of 1963. He had been engaged full time as an advisor in the field of financial investment planning, and was judged to be functioning quite well.

\section{DISCUSSION}

A detailed account of the clinical and pathological features of acute haemorrhagic leucoencephalitis will not be given because adequate reviews have already been published (Crawford, 1954; Lander, 1958; Kulick, 1960). Brief consideration of some of the important points, however, is germane to this presentation.

Acute haemorrhagic leucoencephalitis has a predilection for young healthy adults who frequently have had an upper respiratory tract infection during the week or two which preceded the onset of neurological signs and symptoms. The onset of the neuro- 
logical phase is often heralded by headaches; focal cerebral signs and confusion, which rapidly progresses to coma, dominate the clinical course. Death occurs usually within a week following the appearance of neurological signs.

The major lesions are located in the centrum semiovale; the cortex is conspicuously spared. The white matter exhibits petecchial haemorrhages, a polymorphonuclear leucocytic infiltrate, and perivascular demyelination. Essential to the diagnosis, according to Greenfield (1958), is vascular necrosis, with a fibrinous exudate in the walls of the necrotic vessels which extends into the surrounding tissue.

The aetiology of acute haemorrhagic leucoencephalitis is unknown. Of the reported cases, in only two can there be considered adequate attempts at isolation of a virus (Fowler and French, 1949; Southcott and Fowler, 1954). Both attempts failed to effect isolation of a virus; consequently, the viral theory of the aetiology of acute haemorrhagic leucoencephalitis is not widely accepted. A toxic aetiology has been considered, but because there is a lack of clinical substantiation, it also has not gained general acceptance. The theory most widely accepted postulates an immunological mechanism as the means by which central nervous system tissue is injured (Greenfield, 1950; Crawford, 1954; Russell, 1955; Coxe and Luse, 1963; Mackay and Burnet, 1963; Pearson, 1963).

The evidence which implicates an antigen-antibody reaction in the aetiology of haemorrhagic leucoencephalitis has indeed accumulated to convincing proportions. For example, the demyelinating perivascular lesions resemble those which occur in simian experimental allergic encephalomyelitis (Wolf, 1963). In addition, although there is little evidence for a circulating antibody being the agent responsible for diseases which are considered to be immunologically induced, such as experimental allergic encephalomyelitis and post-vaccinal encephalomyelitis, the fibrinoid necrosis of blood vessels, the fibrinous transudate, and the polymorphonuclear leucocytic accumulation at the site of the lesions bring to mind an Arthus phenomenon-type reaction (Lander, 1958; Good, 1963). Additional support for the 'allergic' theory was given by Symmers (1956) who reported the case of a patient with thrombotic thrombocytopenic purpura associated with acute haemorrhagic leucoencephalitis which developed with explosive rapidity following a single application of oxophenarsine to the gums.

The remainder of our discussion will be divided into two parts as follows:-A consideration of the clinical course of acute haemorrhagic leucoencephalitis especially as regards the additional information which was accumulated from the study of our patient, and an assessment of the significance of the concur rence of a primary herpes simplex infection with acuto haemorrhagic leucoencephalitis.

The presenting signs and symptoms of acute haemorrhagic leucoencephalatis are non-specific their focal nature and rapid progression may often prompt the diagnosis of a cerebral abscess or s neoplasm. Shift of the intracranial structures by the encephalitic process as revealed by contrast radio graphs would support a diagnosis of one of the more. common space-occupying lesions. In recent years however, the neurosurgeon is becoming increasingly aware of the distinct possibility that unilateraE expanding lesions, especially of the temporal and adjacent partietal regions, can be secondary to vira encephalitides and other encephalitides of unknown aetiology (Kristiansen, Harkmark, and Cohen, 1956, Haymaker, Smith, van Bogaert, and de Chenar, $\vec{A}$ 1958; Bennett, ZuRhein, and Roberts, 1962; Coxe and Luse, 1963).

Nevertheless, pre-operatively our patient was considered to have had a diffuse glioma. Relief of the increased intracranial pressure and prevention of its sequelae were of immediate concern, and so thes patient was taken to surgery forthwith. Amputationis of the temporal lobe afforded adequate internal 雲 $-\omega$ compression. Dural closure and replacement of bone flap would have been impossible, in opiropinion, had we not used hyperventilation during aesthesia and had we not amputated the temporap lobe. Successful relief of the intracranial spges problem is implied by the relatively benign post-: operative course of events.

One might assume from our experience, and thes experience of others (Coxe and Luse, 1963), not only ${ }^{+}$ that some patients with acute haemorrhagic leuco-o encephalitis can be operated upon and survive buts also that the course of the disease in some patients may be favourably altered by operative intervention In support of this conjecture we call to attention $a_{\stackrel{\mathbb{Q}}{\mathbb{Q}}}$ number of reports which implicate vascular com $-\overrightarrow{\vec{F}}$ pression from a swollen brain as contributing to the lesions seen in head injuries (Lindenberg, 1955) and the necrotizing encephalitides (Grant and Mc=음 Menemey, 1961; Woolf and Hoult, 1961). It seems reasonable to propose, therefore, that some patients with acute haemorrhagic leucoencephalitis would? benefit from a timely decompression which wouldB effect interruption of a cycle of brain swelling $\rightarrow$ c vascular compromise $\rightarrow$ brain swelling. We recognize the obvious existence, however, of a group of patients in whom the primary process has destroyed vital centres and in whom surgery could do no good.

To consider briefly, now, some of the long-term follow-up features in our patient, we note initiallyo the absence of any evidence to indicate a recrudesc $-\pi$ 
ence of the disease process. The patient has presented, thus far, clinical evidence of only a single self-limiting episode which was followed by partial recovery.

Although evaluation of the patient's deficits is complicated somewhat by the effects consequent on the temporal lobectomy, most of the residual signs are compatible with non-progressive lesions in the non-dominant parietal lobe. The hemianopsia and the impaired cortical sensory interpretation can be adequately explained by lesions which have interrupted the projectional and associational tracts from cortical areas and the tracts connecting thalamus with cortex. The various laboratory studies performed (analysis of cerebrospinal fluid, serum, urine, and a brain scan) were normal in the late convalescent phase. Hoping to detect some specific abnormality, such as is seen in Dawson's inclusion body encephalitis, we carefully scrutinized the electroencephalograms but observed only nonspecific changes. In summary, we have been unable to detect clinical or laboratory evidence of unique or distinguishing sequelae which would permit the retrospective diagnosis of acute haemorrhagic leucoencephalitis.

The significance of the association of acute haemorrhagic leucoencephalitis with a primary herpes simplex infection remains to be analysed. Even if one accepts as valid the recorded rise in complement-fixing antibody from a titre of less than $1: 8$ to $1: 32$ during the course of the illness, the accuracy and specificity of this serological test must be defined in order for the test results to be meaningful. Consensus of authoritative opinion holds that the demonstration of a four-fold or greater rise in complement-fixing antibody titre to herpes simplex establishes the laboratory diagnosis of a herpes simplex infection (Hayward, 1950; Rivers and Horsfall, 1959; Bedson, Downie, MacCallum, and Stuart-Harris, 1961; Schmidt and Lennette, 1961; McAllister, 1962; Rhodes and van Rooyen, 1962; Dudgeon, 1963). In fact many investigators have used as the sole criterion for the establishment of the diagnosis of herpes simplex encephalitis a rising complement-fixing antibody titre (Afzelius-Alm, 1951; Haymaker et al., 1958; Ross and Stevenson, 1961; Drachman and Adams, 1962). Moreover, Gajdusek, Robbins, and Robbins (1952) recorded a four-fold or greater rise in complement-fixing antibody titres only in patients with primary herpes simplex infections. Complement-fixing antibody titres in their patients with recurrent herpes simplex infections rose insignificantly (less than four-fold) or not at all.

Hence, there is ample evidence to support a diagnosis in our patient of a primary herpes simplex infection. The role of herpes simplex in the patho- genesis of acute haemorrhagic leucoencephalitis, however, is únclear. Often a frequent source of confusion, the virus of herpes simplex occupies a unique place among the agents which infect man. It can lie dormant in tissues; following non-specific stimuli (fever, sunlight, stress) recurrent lesions develop despite the presence of circulating antibody. Herpes simplex has been isolated incidentally from cerebrospinal fluid and brain. Its ubiquitous distribution in man is attested to by the presence of anti-herpes simplex antibodies in approximately $90 \%$ of adults (Buddingh, Schrum, Lanier, and Guidry, 1953), and it can be isolated from the mouths of many individuals with no clinical evidence of infection.

A primary herpes simplex infection can present in a number of ways. The virus may cause lesions of the skin or mucous membranes, either localized (herpes febrilis; herpetic gingivostomatitis) or disseminated (eczema herpeticum). A systemic herpes simplex infection, especially in infants, can predominantly involve the liver and adrenal glands. Finally, the central nervous system may react to an infection by exhibiting a meningitis and/or an encephalitis. According to Lennette (1958), herpes simplex encephalitis is probably caused by a primary rather than a recurrent infection, although evidence in support of either contention is meagre.

Herpes simplex encephalitis may be a benign illness with a short self-limited course ending in complete recovery in which case the diagnosis is made by the demonstration of a rise in the serum antibody titre (Afzelius-Alm, 1951; Ross and Stevenson, 1961). In the rapidly progressive fatal cases, the diagnosis has been established by the isolation of the virus from the brain (Smith, Lennette, and Reames, 1941; Zarafonetis, Smadel, Adams, and Haymaker, 1944; Whitman, Wall, and Warren, 1946; Haymaker, 1949; Haymaker et al., 1958). Fatal herpes simplex encephalitis is characterized by the abrupt onset of headache. Focal cerebral signs and coma rapidly progress to death which usually occurs within two weeks of onset. More often than not, examination of the brain discloses extensive softening and necrosis of the cerebral cortex, with the major lesions usually located in the temporal lobe. The white matter in the subcortical regions is also affected, but in general the white matter suffers much less than the grey. The appearance of the lesions frequently suggests ischaemic necrosis (Haymaker, 1949). A characteristic feature of herpes simplex encephalitis is the presence of Cowdry type $A$ intranuclear inclusions in the neurons and the oligodendroglia.

We note the obvious lack of similarity between the lesions of herpes simplex encephalitis and those of acute haemorrhagic leucoencephalitis; therefore, 
having concluded that the pathogenesis of acute haemorrhagic leucoencephalitis is probably based upon an immunoligical mechanism, and having cited evidence which fails to support the contention that herpes simplex by direct effect causes the disease, we are left with the task of explaining the coexistence in our patient of acute haemorrhagic leucoencephalitis and a primary herpes simplex infection.

Assuming that the rise in complement-fixing antibody was indeed indicative of a primary herpes simplex infection, an assumption supported by experience (Gajdusek et al., 1952; and others previously cited), and not simply a non-specific anamnestic response, we have considered three main possibilities:

1 An occult primary mucocutaneous herpetic infection may have occurred which was entirely coincidental to the development of acute haemorrhagic leucoencephalitis. While we cannot exclude this explanation, the law of probability is against chance association, particularly in view of the ability of herpes simplex to effect nervous system lesions.

2 Primary infection with herpes simplex, by direct effect on the central nervous system, may in certain individuals cause the lesions of acute haemorrhagic leucoencephalitis; such a conclusion is supported by our finding of what we interpret as Cowdry type A intranuclear inclusions in the oligodendroglia. The acknowledged wide range of human host response to herpes simplex renders the addition of yet another type of tissue response not unreasonable.

3 Through an immunological mechanism, the virus precipitated acute haemorrhagic leucoencephalitis either by acting as a hapten, combining with host tissue to form an antigen which the host's immunologically competent cells do not recognize as 'self', or rendering a normally inaccessible autologous antigen accessible to the host's immunologically competent cells.

Inasmuch as acute haemorrhagic leucoencephalitis is a rare entity and survival therefrom even rarer, we have felt justified in presenting our observations of one patient in the hope that they may, by adding a modicum of new information, increase the understanding of the diverse encephalitides and demyelinating diseases. Whether or not any one of the aforementioned explanations for the association we recorded between herpes simplex and acute haemorrhagic leucoencephalitis is valid must remain open to question until such time as additional experience accumulates and permits confirmation or refutation of our observations and speculations.

\section{SUMMARY}

A case history has been presented of a patient who developed acute haemorrhagic leucoencephalitis recovered, and was available two-and-a-half yeare later for follow-up evaluation. The diagnosis was established upon examination of an amputate temporal lobe. In addition, a rise of the serune complement-fixing antibody titre to herpes simplex established the diagnosis of a concurrent primats herpes simplex infection.

We have come to the following conclusions base upon the information gathered from the study of this patient together with a review of the pertinen literature:

1 Surgical decompression in the early stages selected cases of acute haemorrhagic leucoencepha $\frac{5}{5}$. itis may facilitate recovery. 2 Because the abnormal ties observed are non-specific, laboratory and clinicat study of the patient who has recovered from acute haemorrhagic leucoencephalitis will not perm $\vec{\phi}$ retrospective diagnosis. 3 The response of somet individuals to herpes simplex virus infection mase result in acute haemorrhagic leucoencephalits either by direct effect of the virus on the tissue of through an ill-defined immunological mechanisnin 4 Herpes simplex may possibly play a more importand role in the aetiology of diseases of the nervous system than has heretofore been appreciated.

The authors are indebted to Dr. Joseph Taber for assistance in interpreting the electroencephalograms

\section{REFERENCES}

Afzelius-Alm, L. (1951). Aseptic (nonbacterial) encephalomeng( in Gothenburg, 1932-1950. Acta med. scand., suppl. 263. Bedson, S., Downie, A. W., MacCallum, F. O., and Stuart-Harrș C. H. (1961). Virus and Rickettsial Diseases of Man, 3rd ed., p. 122. Arnold, London.

Bennett, D. R., ZuRhein, G. M., and Roberts, T. S. (1962). Acu necrotizing encephalitis: A diagnostic problem in tempor lobe disease. Arch. Neurol. (Chic.), 6, 96-113.

Buddingh, G. J., Schrum, D. I., Lanier, J. C., and Guidry, D. (1953). Studies of the natural history of herpes simplex infe? tions. Pediatrics, 11, 595-610.

Coxe, W. S., and Luse, S. A. (1963). Acute hemorrhagic leukoence phalitis: A clinical and electron-microscopic report of $\frac{\vec{B}}{3}$ patients treated with surgical decompression. J. Neurosurg 20, 584-596.

Crawford, T. (1954). Acute hemorrhagic leuco-encephalitis. J. cli Path., 7, 1-9.

Drachman, D. A., and Adams, R. D. (1962). Herpes simplex and acute inclusion-body encephalitis. Arch. Neurol. (Chic 7, 45-63.

Dudgeon, J. A. (1963). Virus encephalitis. Proc. roy. Soc. Med., 58. 537-541.

Fowler, M., and French, E. L. (1949). A case of acute haemorrhagix. leucoencephalitis (Hurst) following a typical pneumonia, with a description of cultural and virus studies. Med. J. Aus? 1, 267-271.

Gajdusek, D. C., Robbins, M. L., and Robbins, F. C. (1952). Diagnosis of herpes simplex infections by the complement fixation test J. Amer. med. Ass., 149, 235-240.

Good, R. A. (1963). Experimental allergic encephalomyelitis: $\frac{\vec{Q}}{Q}$ model for study of pathology, pathogenesis, prevention, and treatment of auto-immune diseases. In Mechanisms of Demyetio nation, edited by A. Rose and C. Pearson, pp. 146-1692 McGraw-Hill, New York, Toronto, London. 
Grant, H. G., and McMenemey, W. H. (1961). A case of necrotizing encephalitis. In Encephalitides: Proceedings of a Symposium on the Neuropathology, Electroencephalography and Biochemistry of Encephalitides, Antwerp, 1959, edited by L. van Bogaert et al. pp. 227-229. Elsevier, Amsterdam.

Greenfield, J. G. (1950). Encephalitis and encephalomyelitis in England and Wales during the last decade. Brain, 73, 141-166.

- (1958). Acute haemorrhagic leucoencephalitis. In Neuropathology by Greenfield, J. G., Blackwood, W., McMenemey, W. H., Meyer, A., and Norman, R. M. pp. 205-207. Arnold, London.

t.aymaker, W. (1949). Herpes simplex encephalitis in man, with report of three cases. $J$. Neuropath. exp. Neurol., 8, 132-154.

_- Smith, M. G., van Bogaert, L., and de Chenar, C. (1958). In Viral Encephalitis: a Symposium, edited by W. S. Fields and R. J. Blattner, pp. 95-204. Thomas, Springfield, Illinois.

Hayward, M. E. (1950). Serological diagnosis of herpes simplex infections. Lancet, 1, 856-858.

Hurst. E. W. (1941). Acute haemorrhagic leucoencephalitis: A previously undefined entity. Med. J. Aust., 2, 1-6.

Kristiansen, K., Harkmark, W., and Cohen, M. M. (1956). Acute haemorrhagic encephalitis. Neurology (Minneap.), 6, 503-509.

Kulick, S. A. (1960). Acute haemorrhagic leukoencephalitis: Report of a case and review of the literature. Boston med. Quart., 11, 120-130.

Lander, H. (1958). Acute Haemorrhagic leuco-encephalitis. Aust. Ann. Med., 7, 55-68.

Lennette, E. H. (1958). In Viral Encephalitis; a Symposium, edited by W. Fields and R. Blattner, p. 202. Thomas, Springfield, Illinois.

Lindenberg, R. (1955). Compression of brain arteries as pathogenetic factor for tissue necroses and their areas of predilection. J. Neuropath. exp. Neurol., 14, 223-243.

Mackay, I. R., and Burnet, F. M. (1963). Autoimmune Diseases, pp. 167-181. Thomas, Springfield, Illinois.

McAllister, R. M. (1962). Viral encephalitides. Ann. Rev. Med., 13, 404-405.

Pearson, C. M. (1963). Hypersensitivity mechanisms in man and animals. In Mechanisms of Demyelination, edited by A. Rose and C. Pearson, pp. 93-118. McGraw-Hill, New York, Toronto, London.
Rhodes, A. J., and van Rooyen, C. E. (1962). Textbook of Virology. 4th ed. Williams and Wilkins, Baltimore.

Rivers, T. M., and Horsfall, F. L. Jr. (1959). Viral and Rickettsial Infections of Man. 3rd ed. Lippincott, Philadelphia.

Ross, C. A. C., and Stevenson, J. (1961). Herpes-simplex meningoencephalitis. Lancet, 2, 682-685.

Russell, D. S. (1955). The nosological unity of acute haemorrhagic leucoencephalitis and acute disseminated encephalomyelitis. Brain, 78, 369-376.

Schmidt, N. J., and Lennette, E. H. (1961). A colorimetric neutralization test for herpes simplex, with observations on the neutralizing and complement-fixing antibody levels in human sera. J. Immunol., 86, 137-145.

Smith, M. G., Lennette, E. H., and Reames, H. R. (1941). Isolation of the virus of herpes simplex and the demonstration of intranuclear inclusions in a case of acute encephalitis. Amer. $J$. Path., 17, 55-68.

Southcott, R. V., and Fowler, M. (1954). A further case of acute haemorrhagic leucoencephalitis (Hurst). Med. J. Aust., 2 , 65-68.

Symmers, W. St. C. (1956). Thrombotic microangiopathy (thrombotic thrombocytopenic purpura) associated with acute haemorrhagic leucoencephalitis and sensitivity to oxophenarsine. Brain, 79, 511-521.

Whitman, L., Wall, M. J., and Warren, J. (1946). Herpes simplex encephalitis: A report of two fatal cases. J. Amer. med. Ass. 131, 1408-1411.

Wolf, A. (1963). Spontaneous human and experimental simian demyelinating disease. In Mechanisms of Demyelination, edited by A. Rose and C. Pearson, pp. 72-92. McGraw-Hill, New York, Toronto, London.

Woolf, A. L., and Hoult, J. G. (1961). Atypical encephalitides. In Encephalitides: Proceedings of a Symposium on the Neuropathology, Electroencephalography and Biochemistry of Encephalitides, Antwerp, 1959, edited by L. van Bogaert et al., pp. 315-324. Elsevier, Amsterdam.

Zarafonetis, C. J. D., Smadel, J. E., Adams, J. W., and Haymaker, W. (1944). Fatal herpes simplex encephalitis in man. Amer. J. Path., 20, 429-445. 